DIGITALCOMMONS @WAYNESTATE-
Michigan Journal of Counseling:

Research, Theory and Practice

Volume 31 | Issue 2

Article 3

$10-1-2003$

\title{
The Counselor As Expert Witness: Changes in the Michigan Hearsay Rule
}

John J. Pietrofesa

Wayne State University, aa3222@weyne.edu

Cathy J. Pietrofesa

John David Pietrofesa

Follow this and additional works at: https://digitalcommons.wayne.edu/mijoc

\section{Recommended Citation}

Pietrofesa, J. J., Pietrofesa, C. J., \& Pietrofesa, J. D. (2003). The Counselor As Expert Witness: Changes in the Michigan Hearsay Rule, Dimensions of Counseling, 31(2), 13-16. doi:10.22237/mijoc/1064966520

This Article is brought to you for free and open access by the Open Access Journals at DigitalCommons@WayneState. It has been accepted for inclusion in Michigan Journal of Counseling: Research, Theory and Practice by an authorized editor of DigitalCommons@WayneState. 


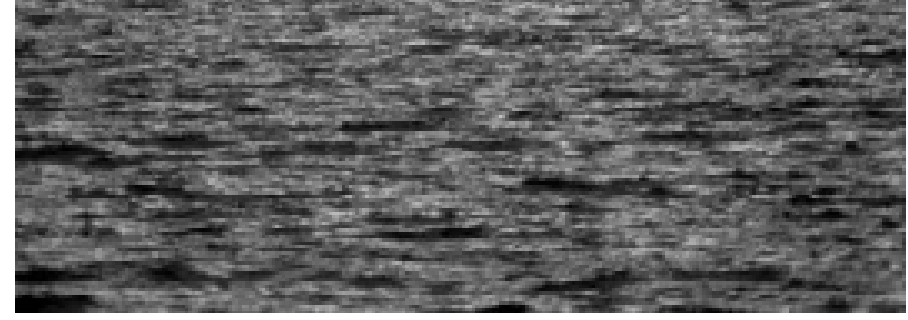

\section{The Counselor As Expert Witness: Changes in the Michigan Hearsay Rule}

\section{John J. Pietrofesa, Ed.D.}

\section{Cathy J. Pietrofesa, Ph.D.}

\section{John David Pietrofesa, J.D.}

\section{John Pietrofesa is a Professor in Counselor Education at Wayne}

State University. Cathy Pietrofesa is a Psychologist in practice in Michigan, and John David Pietrofesa is an Assistant Prosecutor in Michigan. Correspondence regarding this article can be directed to John Pietrofesa, at Counselor Education, 321

Education, Wayne State University, Detroit, Michigan 48202 or ataa3222@weyne.edu
This article discusses the expanding role of the professional counselor as expert witness. The preferred role of the expert witness is one in which the expert informatively presents the facts and does not act as an advocate trying to influence a legal decision. The expert witness in Michigan now has to consider changes in the Michigan Rules of Evidence which disallows any hearsay evidence the counselor may have acquired during counseling. Additionally, supporting documentation for opinions may not simply be cited, but must be placed into evidence. This article concludes with suggestions for counselors in preparing for the role as expert witness in the courts. hat was once an uneasy alliance between legal and mental health professionals has evolved into the frequent use of counselors, psychologists, social workers, and psychiatrists as expert witnesses. Social changes have contributed considerably to this evolution. Due to the increase in issues such as violence, divorce, custody disputes, and substance use, mental health professionals have been increasingly accepted in the role of expert witness.

There have been several recent examples in the courts where counselors were asked to provide expert opinions. The first situation involved a case in which the custodial parent wanted to move out of the state with her children so that she could be closer to her parents. The father objected because this would impact his parenting time. The counselor was asked to provide an expert opinion as to the emotional and social impact this would have upon the children. The second situation involved a family in 
which an adolescent made a false accusation of sexual touching against a step-parent. The court requested the family to undergo individual and family assessments followed by a hearing in which the counselor would offer opinions that would help the court in its rulings. The third situation involved a custodial dispute about parenting time for three children. The counselor was asked to provide an expert opinion as to what was in the children's best interests given the adversarial nature of the parents' relationship.

The role as expert witness is not without its challenges. What often occurs in the courts is an advocacy process in which an expert witness can be viewed as either for or against plaintiff or client. Yet, while the ideal role of the expert witness is one of "a detached, thoroughly neutral individual who simply and informatively presents the true facts as he/she sees them; the undesirable role is that of a partisan seeking to undermine the opponent acting deceptively to present his [sic] case more favorably and behaving in a variety of unethical, inappropriate ways for reasons of greed, maladjustment, or personal aggrandizement" (Brodsky and Robey, 1972, p. 173).

Expert witnesses, many of whom are counselors, participate in a plethora of legal cases. Their testimonies have significant impact since as Faust and Ziskin (1988) say, "based upon an expert's opinion, individuals may be confined to hospitals, obtain or lose custody or guardianship, or be placed in penal institutions or rehabilitation facilities" (p.241). The need for fairness and impartiality is clearly seen in how such testimony will affect the lives of people. The generally accepted standards for clinicians as expert would include: (1) the expert is able to offer opinions with reasonable clinical certainty, and (2) the testimony is offered to help a judge or jury be better able to reach a more informed decision than in the absence of such testimony. Questions are still raised about the accuracy of counseling and clinical judgments and if they indeed help judges and juries arrive at more informed conclusions. As a result, the mental health professional must take the greatest of care in arriving at judgments to be offered in the legal arena.

\section{The Michigan Hearsay Rule Change}

The professional counselor is perhaps most likely to be asked to serve as an expert witness in cases that involve custody, divorce, drug and alcohol use, child abuse, domestic abuse, pain and suffering as a result of an accident, sexual harassment and workers compensation. Traditionally, the counselor as an expert witness has been able to testify not only about facts in evidence, but also about what others have said to them. For example, statements made by an adult or child in a custody case have been admissible as evidence.

On March 25, 2003, the Michigan Supreme Court changed what is to be allowed into evidence, effective as of September 1, 2003. The Michigan Rules of Evidence (MRE) and specifically Rule 703 previously read as follows:

The facts or data in the particular case upon which an expert bases an opinion of inference may be those perceived by or made known to the expert at or before the hearing shall be in evidence. The court may require that underlying facts or data essential to an opinion or inference be in evidence. This rule does not restrict the discretion of the court to receive expert opinion testimony subject to the condition that the factual bases of the opinion be admitted in evidence thereafter.

With the change that became effective on September, 2003, Rule 703 now reads as follows:

\section{The facts or data in the particular case upon which an expert bases an opinion or inference shall be in evidence.}

This change essentially disallows as evidence hearsay information that the counselor may have received during counseling sessions. Additionally, mental health professionals will have to place into evidence supporting documentation for any research cited and the basis upon which recommendations are made. An extreme possibility would be that the person who conducted referenced research would be called to testify. The staff comment (Michigan Supreme Court, 2003) on the modification of MRE 703 specifically states that this "corrects a common misreading of the rule by allowing an expert's opinion only if that opinion is based exclusively on evidence that has been introduced into evidence in some other way than through the expert's hearsay testimony (p.2)." Although there are some exceptions to the new hearsay rule, it is important not to minimize the impact of this change in the MRE. Although opinions can still be rendered under this change, it will considerably curtail the role of all mental health professionals as expert witnesses. Exceptions to this change in the allowance of hearsay testimony might 
include a Friend of the Court report that includes evaluations by outside persons or agencies or a brief submitted to the Friend of the Court. Preliminary mental health hearings conducted by a probate judge which included hearsay testimony might also be allowable under the new Rules of Evidence.

\section{Preparation for the Role of the Expert Witness}

The role of expert witness will bring new challenges for a counselor and the need for additional training. Huber and Baruth (1987) note that, "The legally naïve therapist will likely experience frustration and embarrassment at the hands of a skilled and well-prepared attorney within the adversarial system of the court (p.125)". Specifically, the counselor would want to be knowledgeable in the rules of evidence that are used in the courtroom. Prior training in providing courtroom testimony is essential to the expert's effectiveness. While nothing is more important for the expert witness than a firm grasp of psychological dynamics and counseling fundamentals, it is important to have legal and forensic training.

With these changes regarding the rules of evidence, counselors as expert witnesses may want to consider several suggestions for their role in court. Fundamentally, the counselor should carefully review the case file and be familiar with the client's previous statements and behaviors. If a video is available of any client interviews with attorneys, watch them carefully and observe behavior and manner of speech. A copy of the opposing expert's report and credentials might also be obtained to prepare the presentation. Clinical records may be subpoenaed. They should be reviewed carefully, but obviously may not be changed as falsification of health records is both unethical and illegal.

The counselor will want to consult with the attorney before testifying. There should be some prior understanding of what to expect during direct examination, what aspects should be highlighted and where potential problems may be. It is important to know what legal issues are in dispute and what to anticipate from the opposing attorney. At this time, the counselor as expert witness can point out to the "non-expert" attorney other issues of which the attorney may not be aware.

During testimony the counselor should have available all reports and other information upon which his or her testimony is based. Although some anxiety is to be expected, it is helpful for the counselor to maintain eye contact with the jury. It is important to be responsive, but not appear to be playing for the jurors' benefit. The expert should not talk "down" to the "nonexpert" attorneys because the judge and jurors are in the same situation.

Psychological terms can be used, but they should also be explained and / or used with specific, well-known examples. It is important to answer the specific question asked but not to expand or volunteer information. Upon cross-examination, the expert will want to maintain appropriate demeanor and continue to provide fair and impartial responses without becoming defensive or argumentative. It is essential not to change the facts of the case during cross-examination. If the facts change, the conclusions drawn will also change.

The expert witness will want to be present during the testimony of the opposing expert. Facts offered by the other expert(s) may be supportive. Similarly, the counselor will want to review and be familiar with the client's former psychological care and treatment including an understanding of previously prescribed medications.

If tests were administered, the counselor will want to explain the relevance of the protocol and the reasons that other tests, especially if they were used by the opposing experts, were not. The counselor should be prepared to provide some detail about how the tests can detect malingering or deception on the part of the client during the testing and should also be willing to admit to the weaknesses of the tests. It is important to remember that any test, particularly if questions are taken out of context, may be challenged during cross-examination and the expert should therefore be prepared to non-defensively explain the validity and reliability of tests used.

The factors that led to diagnosis and course of treatment should be explained firmly. In offering a DSM IV treatment diagnosis, the counselor should also be prepared to address differential diagnosis issues and why they were ruled out. Although there is a clear explanation of the diagnosis and treatment, some time should also be spent on the possibility of recovery or change.

\section{Conclusion}

It is important to recognize the expanding role of counselors that now includes potentially being called as an expert witness. The Michigan Supreme Court has issued an order that testimony by experts cannot be based 
upon hearsay with limited exceptions. This alteration in the Rules of Evidence will have considerable impact on what expert witnesses might be able to testify to in courts. This will have the greatest impact upon counselors who might testify in Family Court and who can no longer testify about what was said to them during counseling sessions.

\section{References}

Brodsky, S.L. \& Robey, A. (1972). On Becoming an Expert Witness: Issues of Orientation and Effectiveness. Professional Psychology, 3, 173-176.

Corey, G. and Corey, M.S. (1998). Issues and Ethics in the Helping Professions. Pacific Grove, CA: Brooks/Cole.

Faust, D. \& Ziskin, J. (1988). The Expert Witness in Psychology and Psychiatry. Science, 241, 31-35.

Huber, C.H. \& Baruth, L.G. (1987). Ethical, Legal, and Professional Issues in the Practice of Marriage and Family therapy. Columbus, OH: Merrill.

Michigan Supreme Court. (2003) Amendment of Rules 703 and 1101 of the Michigan Rules of Evidence. Order Entered March 25, 2003.

Lansing, MI: State of Michigan.

State of Michigan. (2003) Michigan Compiled Laws Annotated. Lansing: State of Michigan. 